\title{
Knowledge and Practice Regarding Renewal of License among Staff Nurses
}

\author{
Liji Sara Varghese ${ }^{1}$, Packialakshmi.K ${ }^{2}$, Tharani. $\mathbf{P}^{3}$, Suvetha.S ${ }^{4}$, Swathi.. ${ }^{5}$, \\ Vanishree. $M^{6}$ \\ ${ }^{1}$ Associate Professor, ${ }^{2}$ Assistant Professor, ${ }^{3-6}$ Fourth Year B.Sc. (N) Students, \\ Faculty of Nursing, Dr. MGR Educational \&Research Institute, Chennai \\ Corresponding Author Liji Sara Varghese
}

\begin{abstract}
Background: A nurse is a healthcare professional who is responsible for the treatment, safety, recovery, and the overall care of a patient. Nurses advocate for health promotion, educate patients and the public on the prevention of illness and injury, provide care and assist in cure, participate in rehabilitation, and provide support. No other health care professional has such a broad and far-reaching role.
\end{abstract}

Aim: The study was aimed to assess the level of knowledge and practice regarding renewal of license among staff nurses.

Methodology: Non-experimental descriptive research design and non-probability convenient sampling technique was used to select 50 staff nurses. The assessment of the level of knowledge and practice among staff nurses was carried out by self-structured questionnaire and practice checklist.

Result: Assessment of level of knowledge as well as practice regarding renewal of nursing license revealed that $9(18 \%)$ of staff nurses had good knowledge, 39 (78\%) moderate knowledge and $2(4 \%)$ poor knowledge, whereas 17 (34\%) good practice, $32(64 \%)$ poor practice and 1 (2\%) didn't perform renewal of license. It was concluded knowledge regarding nursing license has a significant association with checking of license status at $\mathrm{p}<0.05$ level. On other hand, practice regarding nursing license had no significant association with demographic variables at $\mathrm{p}<0.05$ level.

Conclusion: It is inevitable to gain nursing license and do its renewal, as it will monitor minimum competencies and provides assurance to the public that predetermined standards have been met.

Keywords: Nursing, license, renewal, staff nurses

\section{INTRODUCTION}

"The unique function of the nurse is to assist the individual, sick or well, in the performance of those activities contributing to health or its recovery, (or to a peaceful death) that he would perform unaided if he had the necessary strength, will or knowledge. And to do this in such a way as to help him gain independence as rapidly as possible."- Virginia Henderson.

In Present scenario, most of health evaluations are conducted by nurses. Their involvement, monitoring skills and diligence all around the clock enable doctors to diagnose better and to recommend better treatments. A conscientious nurse has taken early warning signs of potential emergencies, such as heart arrest or breathing failure, therefore many lives have been saved. Nursing is an occupation which, if performed wrongly, may cause public harm, which means that it must be controlled by the government. The method of licensing enables this control and these regulations only guarantee the right to practice for well trained, independent nurses. Nursing theories improve healthcare practitioner's professional status and guide them in their education and research. (Colley, 2003) ${ }^{[1]}$ 
In the world of today, it is important to incorporate theory of nursing into practice. Through her work, Patricia Benner "has provided an essential knowledge of acquiring and directly applying knowledge and skills to nursing practice, education, research and administration". ${ }^{[2]}$ Five career stages, novice, advanced beginner, skilled and competent expert according to Benner's model of skill acquisition. ${ }^{[3]}$ Every stage involves a particular pattern of behavior, thought and performance. The expert nurse has the greatest experience and the beginner nurse has the least experience. ${ }^{[4]}$

Owing to rapid changes in healthcare, along with the growing complexities of stationary treatment, health care managers and health care professionals must carefully focus on how the registered nurse can better achieve optimal education and skills. In each point of the nursing process, professional guidelines define the required level of treatment. It ensures that we take responsibility and retain competence for our clinical decisions and measures throughout our career. The overall score of nurses' professional values was high, according to different surveys. It was supported by research findings that $97.3 \%$ attended continuing education activities; more than $92.2 \%$ of the nurses were familiar with the value of continuing education. ${ }^{[5]}$

As per the directive of Central Government and Indian Nursing Council, Tamilnadu Nurse and Midwives Council introduced "Renewal of License/ Registration Certificate for all the category (RN/RM/ANM-MPHW/HV) from July 2013 onwards". It is mandatory to renew once in 5 years with $150 \mathrm{CNE}$ credit hours. [6]

\section{Statement of the Problem}

A study to assess the knowledge and practice regarding renewal of license among staff nurses at selected hospital.

\section{Objectives}

- To assess the knowledge regarding renewal of license among staff nurses at selected hospital.

- To assess the practice regarding renewal of license among staff nurse at selected hospital.

- To find out association between the level of knowledge and practice regarding renewal of license with selected demographic variables.

\section{Research hypothesis}

RH1: There will be significant association between knowledge and practice regarding renewal of license among staff nurses

\section{Assumption}

1. Nurses may have inadequate knowledge regarding renewal of license.

2. Nurses may have poor level of practice regarding renewal of license.

\section{MATERIALS \& METHODS}

Research Design: A quantitative approach with non-experimental descriptive design was adopted for this study in which the level of knowledge and practice regarding renewal of nursing license among staff nurses were the research variable.

Setting: The setting for the study was selected hospital, Chennai, Tamil Nadu.

Samples size \& Sampling technique: A non-probability convenient sampling technique was adopted to select 50 staff nurses who were working in selected hospital, Chennai, Tamil Nadu.

\section{Sampling Criteria}

- Staff nurses who were working in Chennai

- Staff nurses who were willing to participate in the study.

- Staff nurses who were able to read and write English language.

\section{Tool development}

The instrument used for collection of data were

- Part I: Socio-demographic Proforma

- Part II: Self structured knowledge questionnaire-it consists of 18 questions; 
each item consisted of one right answer and three distractors.

- Part III: Practice checklist- it consist of 6 items

\section{Data collection procedure}

Data was collected after getting approval from the authority. The purpose and duration of the study was explained to the subjects. Informed consent was obtained from the study participants related to the study purpose, type of data, benefits \& procedure of study. The respondents were assured confidentiality of information provided by them. The collected data was analyzed using descriptive \& inferential statistics.

\section{RESULTS}

\section{Description of socio-demographic variables}

The analysis of demographic variables showed that majority $40(80 \%)$ samples within the age group of 20-29 years, larger number $45(90 \%)$ were females and more than half $29(58 \%)$ was graduates. Around 29(58\%) respondents got information about nursing license renewal from online sources, whereas 14(28\%) got information from their working institution. Greater number 49(98\%) agreed that renewal of license was important in their profession and majority $45(90 \%)$ staff nurses had checked their license status, whereas $5(10 \%)$ didn't check their license status.

Assessment of level of knowledge about
renewal of license among staff nurses
Table1: depicts the knowledge of staff nurses regarding the
renewal of nursing license among staff nurses.
\begin{tabular}{|c|c|c|c|}
\hline S.No & Level of Knowledge & $\begin{array}{c}\text { Frequency } \\
(\mathbf{N})\end{array}$ & $\begin{array}{c}\text { Percentage } \\
(\%)\end{array}$ \\
\hline 1 & Poor knowledge (1-8) & 2 & 4 \\
\hline 2 & Moderate knowledge (9-16) & 39 & 78 \\
\hline 3 & Good knowledge (17-24) & 9 & 18 \\
\hline \multicolumn{6}{|c|}{ Total } & $\mathbf{5 0}$ & $\mathbf{1 0 0}$ \\
\hline
\end{tabular}

The study results showed (table1) that more than half respondents $39(78 \%)$ had moderate knowledge, merely $9(18 \%)$ of staff nurses had good knowledge, whereas 2 $(4 \%)$ of staff nurses had poor knowledge.

\section{Assessment of Level of Practice Regarding Renewal of License among Staff Nurses:}

Regarding level of practice on renewal of nursing license (figure:1), majority $32(64 \%)$ of staff nurses had poor practice, only 17 (34\%) of staff nurses had good practice, and $1(2 \%)$ didn't perform renewal of license so far.

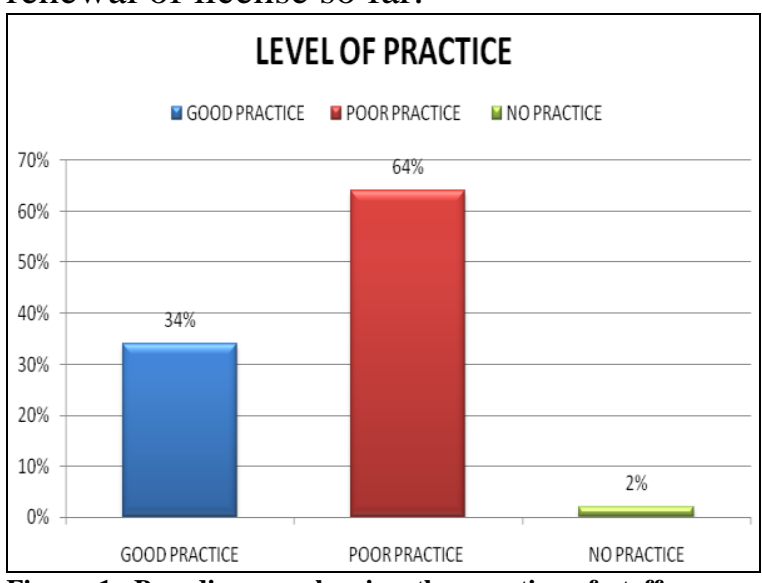

Figure 1: Bar diagram showing the practice of staff nurses regarding renewal of license.

Association between knowledge and practice regarding renewal of license with selected demographic variables

The data concluded that knowledge regarding nursing license has a significant association with checking of license status at $p<0.05$ level. Whereas practice regarding nursing license had no significant association with demographic variables at $\mathrm{p}<0.05$ level

\section{DISCUSSION}

In the current study, participants' level of knowledge showed as 9(18\%) good knowledge, 39(78\%) moderate knowledge and $2(4 \%)$ poor knowledge. Whereas, $17(34 \%)$ had good practice, $32(62 \%)$ poor practice and $1(2 \%)$ didn't perform renewal of license.

Mei Chan Chong, et al (2013) supported current findings that $71 \%$ registered nurses participated in continuing professional practice and $40.9 \%$ of them had achieved the 25 or more credit points required to renew their licenses. ${ }^{[7]}$

Andre K (2010) highlighted that elaborate, e-portfolios have a range of 
potential professional benefits including supporting individuals through a critical reflective approach to competency development, supporting professional collaboration and providing a structure for planning their carrier progression. ${ }^{[8]}$

In these study knowledge regarding nursing license has a significant association with checking of license status at $\mathrm{p}<0.05$ level. It was consistent with previous research work of BatoolPoorchangizi et al. (2017). He stated that there was statistically significant relationship between Nursing Professional Values Scale-Revised (NPVSR) mean scores with their age, professional experience also involvement with professional ethical training $(P<0.05) .{ }^{[9]}$

\section{CONCLUSION}

Continuous education initiatives are recommended to be designated to meet emerging ethical issues. Such services can be a positive step in the implementation of career principles. This will encourage the nursing profession. A licensed nursing license is essential as it sets minimum skills or competencies and assures the public that default requirements are complied with.

Acknowledgement: We would like to thank the College Principal \& participants of this study for their cooperation and support throughout the study.

\section{Conflict of Interest: None}

\section{Source of Funding: None}

Ethical Approval: The Ethical Committee approval was obtained from the Institutional Ethical Committee.

\section{REFERENCE}

1. Colley S. Nursing theory: its importance to practice. Nursing Standard. 2003;17(46):337.

2. Nursing theories [Internet]. From Novice to Expert-Patricia E. Benner. [cited 2021May12]. Available from:
https://currentnursing.com/nursing_theory/P atricia_Benner_From_Novice_to_Expert.ht $\mathrm{ml}$

3. Benner's From Novice to Expert [Internet]. Nursing Theory. 2020 [cited 2021May12]. Available from: https://www.nursingtheory.org/theories-and-models/fromnovice-to-expert.php

4. Dean-Baar S. Every Nurse Has an Idea Worth Writing About. Rehabilitation Nursing. 2001;26(6):206

5. Ni C, Hua Y, Shao P, Wallen GR, Xu S, Li L. Continuing education among Chinese nurses: a general hospital-based study [Internet]. Nurse education today. U.S. National Library of Medicine; 2014 [cited 2021May12]. Available from: https://www.ncbi.nlm.nih.gov/pmc/articles/ PMC3919877/

6. http://www.tamilnadunursingcouncil.com/c ne-process-details.php

7. Chong MC, Francis K, Cooper S, Abdullah KL. Current Continuing Professional Education Practice among Malaysian Nurses [Internet].Nursing research and practice. Hindawi Publishing Corporation; 2014 [cited 2021May12]. Available from: https://www.ncbi.nlm.nih.gov/pmc/articles/ PMC3913040/

8. K; A. E-portfolios for the aspiring professional [Internet]. Collegian (Royal College of Nursing, Australia). U.S. National Library of Medicine; [cited 2021May12]. Available from: https://pubmed.ncbi.nlm.nih.gov/21046965/.

9. Poorchangizi B, Farokhzadian J, Abbaszadeh A, Mirzaee M, Borhani F. The importance of professional values from clinical nurses' perspective in hospitals of a medical university in Iran [Internet]. BMC medical ethics. BioMed Central; 2017 [cited 2021May13]. Available from: https://www.ncbi.nlm.nih.gov/pmc/articles/ PMC5333397/

How to cite this article: Varghese LS, Packialakshmi.K, Tharani.P et.al. Knowledge and practice regarding renewal of license among staff nurses. International Journal of Science \& Healthcare Research. 2021; 6(3): 189-192. DOI: https://doi.org/10.52403/ijshr.20210731 